\title{
Pharmacotherapy of overactive bladder in adults: a review of efficacy, tolerability, and quality of life
}

This article was published in the following Dove Press journal:

Research and Reports in Urology

4 December 2013

Number of times this article has been viewed

Jyotsna Jayarajan

Sidney B Radomski

Division of Urology, Department of Surgery, Toronto Western Hospital (University Health Network), University of Toronto, Toronto, Ontario, Canada
Correspondence: Sidney B Radomski Toronto Western Hospital, Main Pavilion, 8th Floor, Room 304, 399 Bathurst St, Toronto, Ontario, M5T 2S8, Canada Tel + I 4I6 6035800 ext 57/3

Fax + I 4166035391

Email sidney.radomski@uhn.ca
Introduction: Overactive bladder $(\mathrm{OAB})$ is a prevalent condition that has a significant impact on quality of life. The usual treatment approach is both behavioral and pharmacological. The first-line pharmacological treatment commonly utilizes anticholinergic agents, which may be limited by their tolerability, efficacy, and long-term compliance. Developments in elucidating the pathophysiology of $\mathrm{OAB}$ and alternative targets for pharmacological therapy have led to newer agents being developed to manage this condition. These agents include mirabegron and botulinum toxin, which have alternate mechanism of action and avoid the anticholinergic side effects.

Objectives: To provide an update for clinicians managing $\mathrm{OAB}$ with an overview of the existing and newer medical options for OAB, including pharmacology, efficacy, side-effect profile, tolerability, and impact on patient quality of life.

Methods: PubMed and Medline were searched for randomized controlled drug trials in adults with $\mathrm{OAB}$, meta-analyses of medical therapy for $\mathrm{OAB}$, and individual drug names, including the keywords efficacy, tolerability, quality of life, and compliance. Nonhuman studies, pediatric trials, and those involving patients with neurogenic bladder dysfunction (with the exception of studies involving botulinum toxin A) were excluded.

Results: There is level 1, Grade A evidence to support the efficacy of anticholinergic drugs, botulinum toxin, and mirabegron for OAB. Long-term compliance with anticholinergic medications is limited. The mechanism of action, effectiveness, and side effects of these drugs are discussed, and where the data are available compared with other OAB medications.

Conclusion: Most of the anticholinergic agents have comparative efficacies and core side-effect profiles, with individual variations relating to their muscarinic receptor selectivity, pharmacokinetics, and metabolism. Newer agents, with alternative sites of action, such as mirabegron and botulinum toxin, provide additional treatment options for patients intolerant to or inadequately treated with anticholinergics.

Keywords: antimuscarinics, mirabegron, botulinum toxin, incontinence

\section{Introduction}

Overactive bladder $(\mathrm{OAB})$ is a collection of symptoms consisting of urinary urgency (the sudden compelling desire to void that is difficult to defer), frequency and nocturia (usually), and incontinence (sometimes). Urinary frequency is the patient's subjective complaint that he or she voids too often during the day. Nocturia is the need to wake at night once or more to void. Urge urinary incontinence (UI) is involuntary leakage of urine accompanied or immediately preceded by urgency. ${ }^{1}$

OAB is often but not always associated with detrusor overactivity (DO) on urodynamic evaluation. $\mathrm{OAB}$ is a symptom and $\mathrm{DO}$ is an urodynamic finding. OAB may be 
idiopathic (non-neurological) or secondary to a neurological cause (eg, multiple sclerosis, spinal cord injury). Idiopathic $\mathrm{OAB}$ may be due to bladder outlet obstruction, or have no discernible cause. OAB is further subclassified as "OAB wet" if associated with urinary incontinence or "OAB dry" without incontinence. Involuntary DO due to a neurogenic or myogenic cause is often found on urodynamic evaluation of OAB wet.

One large population-based prevalence study reported that approximately $16 \%$ of the general population is affected by OAB. Men are more likely to have OAB dry and females to suffer from $\mathrm{OAB}$ wet. ${ }^{2}$ Both men and women demonstrate an age-related increase in the prevalence of OAB; however, this is more pronounced in women, particularly after the age of 40 . OAB is highly prevalent in the community, and is likely significantly underreported and untreated. OAB has a significant effect on quality of life (QOL), particularly if associated with incontinence.

\section{Background to medical treatment of overactive bladder}

The mainstay of medical therapy for OAB management has been anticholinergic or antimuscarinic medications administered orally. Hormone replacement therapies, tricyclic antidepressants, and desmopressin have also been used for the management of OAB. One of the first anticholinergic medications used for OAB was immediate release (IR) oral oxybutynin (OXY-IR); although it has the drawbacks of multiple daily dosing and bothersome side effects, it is still being used today.

Subsequent numerous anticholinergic formulations have been developed to improve compliance by reducing the required dosing frequency and minimizing the side effect profile. More recent developments include the use of mirabegron, an oral $\beta-3$ adrenergic receptor ( $\beta 3-A R$ ) agonist, and the intravesical administration of botulinum toxin. These agents avoid anticholinergic side effects by their alternative mechanism of action.

\section{Conservative/behavioral management}

The initial management of $\mathrm{OAB}$ is conservative, with or without pharmacotherapy. Pharmacotherapy is more efficacious than behavioral measures; however, in all instances, it should be added to behavioral therapy as the combination of both approaches is more efficacious than either used in isolation. $^{3}$

Conservative measures include: ${ }^{4}$

- Optimizing the management of any underlying medical conditions that may be contributing to symptoms, such as constipation, urinary tract infection, diabetes, cardiac failure, and obstructive sleep apnea

- Managing oral fluid intake - the patient may be counseled regarding the reduction of overall and late evening fluid intake, which may decrease urinary frequency and nocturia. The intake of known diuretics, such as caffeine and alcohol, should be minimized. Caffeine may have a multifactorial and dose-dependent effect on the bladder, with known diuretic and detrusor stimulating properties. Many common food and beverages may contain "hidden" quantities of caffeine

- Timed voiding, during which micturition is not deferred when the urge is felt, and the patient voids regularly at 3-4 hourly or shorter intervals to minimize urgency and urge leakage - the required frequency to effect this symptom improvement may prove to be bothersome in itself

- Bladder retraining techniques that defer micturition for progressively longer durations despite the desire to void, with the aim of reducing urgency and frequency

- Reduction of excessive body weight and smoking cessation.

\section{Clinical assessment and diagnosis}

Prior to making a diagnosis of $\mathrm{OAB}$, the lower urinary tract conditions that may mimic the symptoms of OAB need to be excluded (Table 1).

The basic evaluation of a patient with OAB symptoms includes a history, physical examination, and relevant clinical investigations. On history, the presence, quality, quantity, and degree of bother of lower urinary tract symptoms informs the diagnosis and management.

Clinical investigations should, at the minimum, include urinalysis, postvoid residual urine volume, and bladder diary.

Table I Lower urinary tract conditions that may present with overactive bladder (OAB) symptoms

\footnotetext{
- Infection/Inflammation

- Recurrent urinary tract infection

- Chronic prostatitis

- Interstitial cystitis

- Bladder outlet obstruction

- Urethral stricture

- Benign prostatic hyperplasia

- Bladder pathology

- Bladder cancer

- Bladder calculi

- Behavioral/latrogenic

- Diuresis due to excessive fluid intake, impaired urine concentration, or medications
}

Note: Copyright @2012. The Canadian Journal of Urology. Adapted with permission from Radomski SB, Barkin J. Medical management of overactive bladder. Can J Urol. 2012;19 Suppl 1:2-9. 
A simple 3-day voiding diary, completed by the patient, outlining voiding frequency, timing, and fluid intake can aid with quantifying frequency and nocturia. The identification of excessive or poorly timed fluid intake can guide behavioral recommendations.

\section{Overview of pharmacotherapy for overactive bladder}

The drug classes used to treat $\mathrm{OAB}$ include anticholinergic (antimuscarinic) agents, tricyclic antidepressants, desmopressin, hormone replacement therapy, $\beta 3-\mathrm{AR}$ agonist, and intravesical Botox ${ }^{\circledR}$ (Allergan, Inc., Irvine, CA, USA). The latter two were the most recently introduced.

Anticholinergics (antimuscarinics) have been to date, the mainstay of OAB treatment. Multiple randomized controlled trials have confirmed the effectiveness of these drugs for $\mathrm{OAB}$, therefore recommendations for their use are based on level 1, grade A evidence. Most anticholinergics have a similar side effect profile, which includes dryness of the mouth and eyes, and constipation. As a result of this, other medical therapies have been introduced that do not share this side effect profile (mirabegron, botulinum toxin, and vasopressin).

\section{Sites of overactive bladder drug action: review of the micturition reflex}

The underlying pathophysiology of OAB syndrome is overactivity of the detrusor muscle. The tone of the detrusor muscle during filling and voiding relies on the counterbalance of the autonomic (sympathetic and parasympathetic) nervous system.

The interaction between the autonomic and somatic (pudendal nerves) nervous system facilitates the voluntary control of micturition. During bladder filling, sympathetic stimulation is predominant, with activation of $\beta$-ARs, via fibers of the hypogastric plexus, suppressing detrusor contraction. The bladder derives its motor supply from the sacral nerves $(\mathrm{S} 2,3,4)$ via the parasympathetic nervous system. The release of acetylcholine from parasympathetic postganglionic nerves, mediated by the $\mathrm{M}$ muscarinic receptors, leads to detrusor contraction. Parasympathetic postganglionic nerves also release nonadrenergic, noncholinergic transmitters, such as adenosine triphosphate (ATP) (which has an excitatory action on detrusor muscle, via P2X purinergic receptors). ${ }^{5}$

The pelvic and hypogastric nerves transmit sensory input from the bladder. The sensation of bladder filling is conveyed by myelinated (A $\delta$ ) fibers, whilst unmyelinated $(\mathrm{C})$ axons respond to noxious stimuli. Non-neuronal cells in the urothelium also have sensory and signaling properties that respond to chemical and mechanical stimuli. These cells have various receptors (nicotinic, muscarinic, adrenergic, etc), and release chemical mediators, such as ATP, acetylcholine, and nitric oxide, triggering local vascular response and reflex detrusor contractions via neural-urothelial interaction.

Acetylcholine and ATP released from the urothelium in response to stimuli may induce nonvoiding detrusor contractions, via muscarinic and purinergic receptors, respectively. Urothelial ATP release may also act on the suburothelial myofibroblast layer of the bladder that expresses ATP-gated purinergic $\mathrm{P} 2 \mathrm{Y}$ receptors. ${ }^{5}$

The majority of pharmacotherapies for OAB mediate their action via depressive effects on the detrusor muscle. Increased understanding of the complex neural-urothelial afferent pathways involved with micturition has suggested additional modes of therapeutic action. The anticholinergic agents used in OAB may exert some of their effect by blocking muscarinic receptors in the urothelium or afferent nerves.

Botulinum toxin type A (BoNTA) blocks acetylcholine release at the neuromuscular junction. The mechanism of action in OAB may also reflect action on afferent pathways. Biopsies from patients treated with intradetrusor BoNTA showed normalization of sensory receptors in the suburothelial fibers. In animal models, BoNTA has been shown to reduce distension-evoked urothelial release of ATP. The inhibition of urothelial acetylcholine release and therefore, of ATP release likely reduces the excitatory effect on suburothelial afferent nerves and myofibroblasts during the storage phase of voiding. ${ }^{5}$

\section{Antimuscarinic pharmacotherapy - mechanism of action}

The first-line pharmacotherapy for OAB is most commonly an antimuscarinic agent. The mechanism of action and side effect profile of these drugs relate to their pharmacology. Selective anticholinergics have relatively more affinity for M2 and M3 receptors, which are the most prevalent in the bladder, reducing side effects in the other systems. ${ }^{6}$ Anticholinergics dampen the amplitude of bladder contractions, improving bladder capacity and reducing involuntary detrusor contractions, urgency, and frequency. Observed side effects may include impaired cognition, blurred vision, dry eyes and mouth, and constipation (Table 2$)^{7}$

Anticholinergic medications inhibit the effects of the neurotransmitter acetylcholine in the peripheral and central nervous system (CNS) by blocking either nicotinic or 
Table 2 Anticholinergic effects at various body sites

\begin{tabular}{|c|c|c|c|}
\hline Site & $\begin{array}{l}\text { Muscarinic receptor } \\
\text { subtypes }\end{array}$ & $\begin{array}{l}\text { Effect of receptor blockage } \\
\text { (anticholinergic action) }\end{array}$ & Possible symptoms \\
\hline $\begin{array}{l}\text { Central nervous } \\
\text { system }\end{array}$ & MI (postsynaptic) & $\begin{array}{l}\text { Impaired cognition } \\
\text { Confusion } \\
\text { Sedation }\end{array}$ & $\begin{array}{l}\text { Confusion, impaired } \\
\text { memory/cognition }\end{array}$ \\
\hline $\begin{array}{l}\text { Cardiac muscle and } \\
\text { SA/AV nodes }\end{array}$ & M2 & $\begin{array}{l}\text { Increased AV conduction velocity } \\
\text { and heart rate } \\
\text { Prolongation of QT interval }\end{array}$ & $\begin{array}{l}\text { Cardiac arrhythmias, } \\
\text { tachycardia }\end{array}$ \\
\hline Respiratory & M2, M3 & $\begin{array}{l}\text { Bronchodilation and reduced } \\
\text { mucus secretion }\end{array}$ & $\begin{array}{l}\text { Nasal/throat dryness } \\
\text { Rhinitis }\end{array}$ \\
\hline Gastrointestinal & M2, M3 & $\begin{array}{l}\text { Inhibition of salivation } \\
\text { Reduction of lower esophageal } \\
\text { sphincter tone and gastrointestinal } \\
\text { motility } \\
\text { Reduced gastric secretion }\end{array}$ & $\begin{array}{l}\text { Dry mouth } \\
\text { Constipation }\end{array}$ \\
\hline Genitourinary & $\begin{array}{l}\text { M2 } \\
\text { M3 (mediates detrusor } \\
\text { contraction) }\end{array}$ & Detrusor relaxation & $\begin{array}{l}\text { Reduced voiding } \\
\text { frequency, urgency } \\
\text { Elevation of post } \\
\text { void residual }\end{array}$ \\
\hline Ocular & M3 & $\begin{array}{l}\text { Inhibition of lacrimation } \\
\text { Pupillary dilation and loss of } \\
\text { accommodation (relaxation of } \\
\text { sphincter and ciliary muscle of } \\
\text { the iris) }\end{array}$ & $\begin{array}{l}\text { Dry eyes } \\
\text { Blurred vision }\end{array}$ \\
\hline
\end{tabular}

Abbreviations: AV, atrioventricular; SA, sinoatrial.

muscarinic receptors. Nicotinic receptors are located at the neuromuscular junction in the somatic nervous system and at all autonomic ganglia in the CNS.

Muscarinic receptors are distributed in cardiac muscle, smooth muscle, the CNS, on presynaptic autonomic nerves, and at autonomic ganglia. Activation of the muscarinic receptors inhibits the release of noradrenalin from the nerve terminal. Five types of muscarinic receptors have been identified (M1-5), with varying distribution in tissues. ${ }^{5}$

Due to their mechanism of action, anticholinergics should be used with caution or may be contraindicated in patients with urinary retention, gastric stasis or other conditions with severe impairment of intestinal motility, and uncontrolled narrow-angle glaucoma.

\section{Anticholinergic medications used in overactive bladder Oxybutynin - immediate release}

OXY-IR was the first drug used for OAB and despite newer formulations, is still used in the original IR form today. It is a nonselective antimuscarinic agent that inhibits the effect of acetylcholine on smooth muscle. It causes relaxation of the detrusor muscle but has no effects at the skeletal neuromuscular junction or on the autonomic ganglia.
OXY relaxes bladder smooth muscle. In patients with DO, OXY increases bladder capacity, reduces the frequency of involuntary detrusor contractions, delays the initial desire to void, and reduces urge incontinence. ${ }^{8}$

OXY-IR is rapidly absorbed after ingestion and has a halflife of 2-3 hours. The short half-life necessitates frequent dosing, with a common regime of $2.5-5 \mathrm{mg}$ administered every 8 hours. It undergoes extensive first-pass metabolism in the liver. ${ }^{8}$

The most common side effects at 5-20 mg/day in trials assessing safety and efficacy included dry mouth (71.4\%), constipation (15.1\%), somnolence (14\%) and nausea $(11.6 \%){ }^{8}$ The incidence of dry mouth was dose related. Trials in healthy older patients taking OXY-IR have shown impaired cognition when compared to placebo, other formulations of oxybutynin and other anticholinergics. ${ }^{9}$ The inconvenience of frequent dosing needed to maintain adequate serum levels and the side effect profile led to the development of extended-release (ER) and topical formulations (Table 3).

\section{Oxybutynin - extended release (Ditropan ${ }^{\circledR} \mathrm{XL}$ )}

OXY-ER (Ditropan XL; Janssen Pharmaceuticals, Inc) is available as a $5 \mathrm{mg}, 10 \mathrm{mg}$, or $15 \mathrm{mg}$ once daily formulation. Following the first dose, plasma concen- 
trations rise for 4-6 hours, and unlike the peak-trough plasma concentration of the IR formulation, the levels of OXY-ER remain steady for up to 24 hours. It undergoes first-pass metabolism.

A randomized, double-blind comparison of OXY-ER and OXY-IR for urge urinary incontinence has shown comparable efficacy in the assessed clinical outcomes. ${ }^{10}$ Both OXY-ER and OXY-IR similarly reduced the mean UI episodes per week, mean voiding frequency, and urgency, from baseline (all $P<0.001$ ). Dry mouth was the most common adverse event, reported by $68 \%$ and $72 \%$ of patients in the OXY-ER and OXY-IR groups, respectively. Tolerance was better in the ER group, with a significantly greater number of patients completing the study at a dose of $\geq 15 \mathrm{mg} /$ day with OXY-ER than with OXY-IR $(P=0.018)$. More patients discontinued treatment due to adverse effects in the IR than in the ER group.

Another series showed similar efficacy for the ER and IR formulations but a reduced incidence of dry mouth with the ER formulation (68\% ER vs $87 \%$ IR) $(P=0.03) .{ }^{11}$ The ER formulation offers the convenience of once daily dosing, equivalent efficacy, and better tolerability than the IR formulation.

\section{Oxybutynin - controlled release transdermal patch}

After initial application of the OXY transdermal patch (OXY-TDS), plasma concentrations of OXY increase for 24-48 hours and remain steady for up to 96 hours. Transdermal administration of OXY bypasses first-pass gastrointestinal and hepatic metabolism, resulting in higher average plasma concentrations following single dosing compared with OXY-IR, with lesser anticholinergic side effects. ${ }^{12}$

The combined results of two randomized controlled trials comparing OXY-TDS with placebo found the most common treatment-related adverse reactions were application site pruritus $(16.1 \%)$, application site erythema $(7.0 \%)$, dry mouth (7.0\%), and constipation $(2.1 \%) .^{13}$

A randomized double-blind study comparing OXY-IR with OXY-TDS showed similar efficacy in both groups, regarding reduction in urinary leakage from baseline. ${ }^{14}$ The transdermal preparation, OXY-TDS, was better tolerated, with significantly less dry mouth $(P<0.001)$.

Another double-blind multicenter study compared the efficacy and safety of OXY-TDS or oral extended-release tolterodine (tolterodine-ER) $4 \mathrm{mg}$ daily with placebo. Compared with tolterodine-ER, OXY-TDS demonstrated similar statistically significant improvements in all measured efficacy outcomes, with less systemic adverse effects. ${ }^{15}$

\section{Oxybutynin - topical gel}

Oxybutynin is also available as a topical gel, which is applied once daily to clean, dry skin. Steady state concentrations are achieved within 3 days of continuous dosing. It bypasses first-pass metabolism, like the OXY-TDS.

In a randomized controlled trial to assess safety and efficacy, OXY topical gel (OXY-OTG) significantly reduced UI episodes per week, urinary frequency, and voided volume. ${ }^{16}$ The most common side effects compared with placebo were dry mouth $(6.9 \%)$, application site pruritis $(2.1 \%)$, and application site dermatitis $(1.8 \%)$.

A randomized, double-blind placebo- and activecontrolled study compared the effects of OXY-OTG or OXY-IR versus placebo on cognitive and psychomotor functions in healthy older adults. ${ }^{17}$ There was a significant decline in scores for the Misplaced Objects Test in the OXY-IR group. In the Hopkins Verbal Learning Test-Revised, double the number of OXY-IR patients had a significant decline in their score compared with the other groups. The most common adverse event, dry mouth, occurred in $6.1 \%, 73.1 \%$, and $7.8 \%$ of participants receiving OXY-OTG, OXY-IR, and placebo, respectively.

Thus, compared with OXY-IR, OXY-OTG has equivalent efficacy, with reduced anticholinergic side effects and no clinically meaningful effect on cognitive function in healthy older adults.

\section{Tolterodine tartrate - immediate release and controlled release}

Tolterodine is a competitive muscarinic receptor antagonist available in an IR and ER formulation. Tolterodine-ER is available as a $2 \mathrm{mg}$ or $4 \mathrm{mg}$ daily dose. Tolterodine-IR is dosed at 1-2 mg twice daily (bid).

Tolterodine undergoes hepatic metabolism following oral ingestion, forming a 5-hydroxymethyl (5-HMT) derivative that is pharmacologically active, having similar antimuscarinic activity to tolterodine. Tolterodine and 5-HMT are highly selective for muscarinic receptors. Hepatic and renal insufficiency can significantly alter the metabolism of tolterodine. ${ }^{18}$

A Cochrane review comparing anticholinergic agents for OAB found that compared with OXY, tolterodine had equivalent effects on QOL, patient-reported cure or improvement, leakage episodes, and voids in 24 hours. Tolterodine 


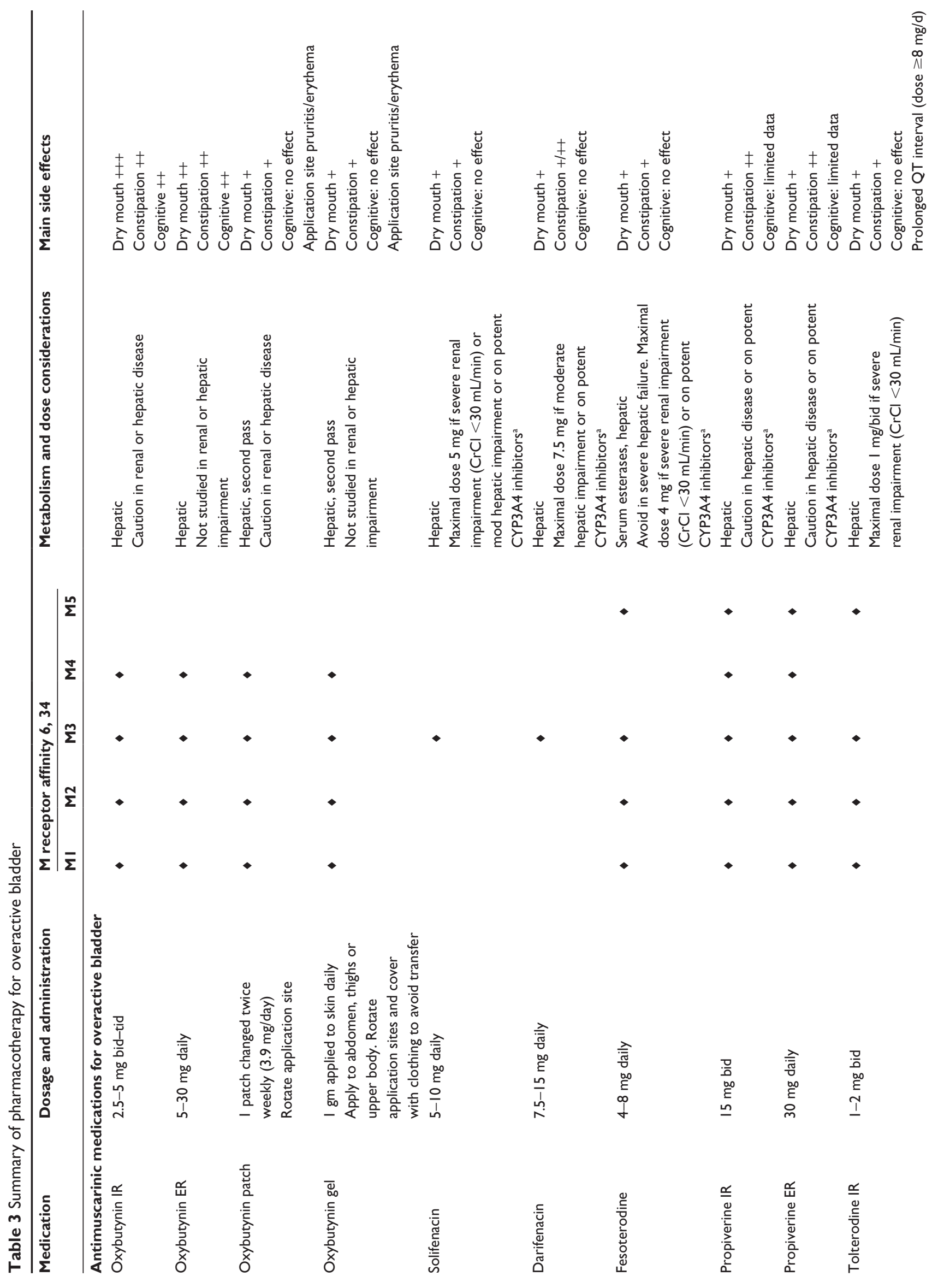




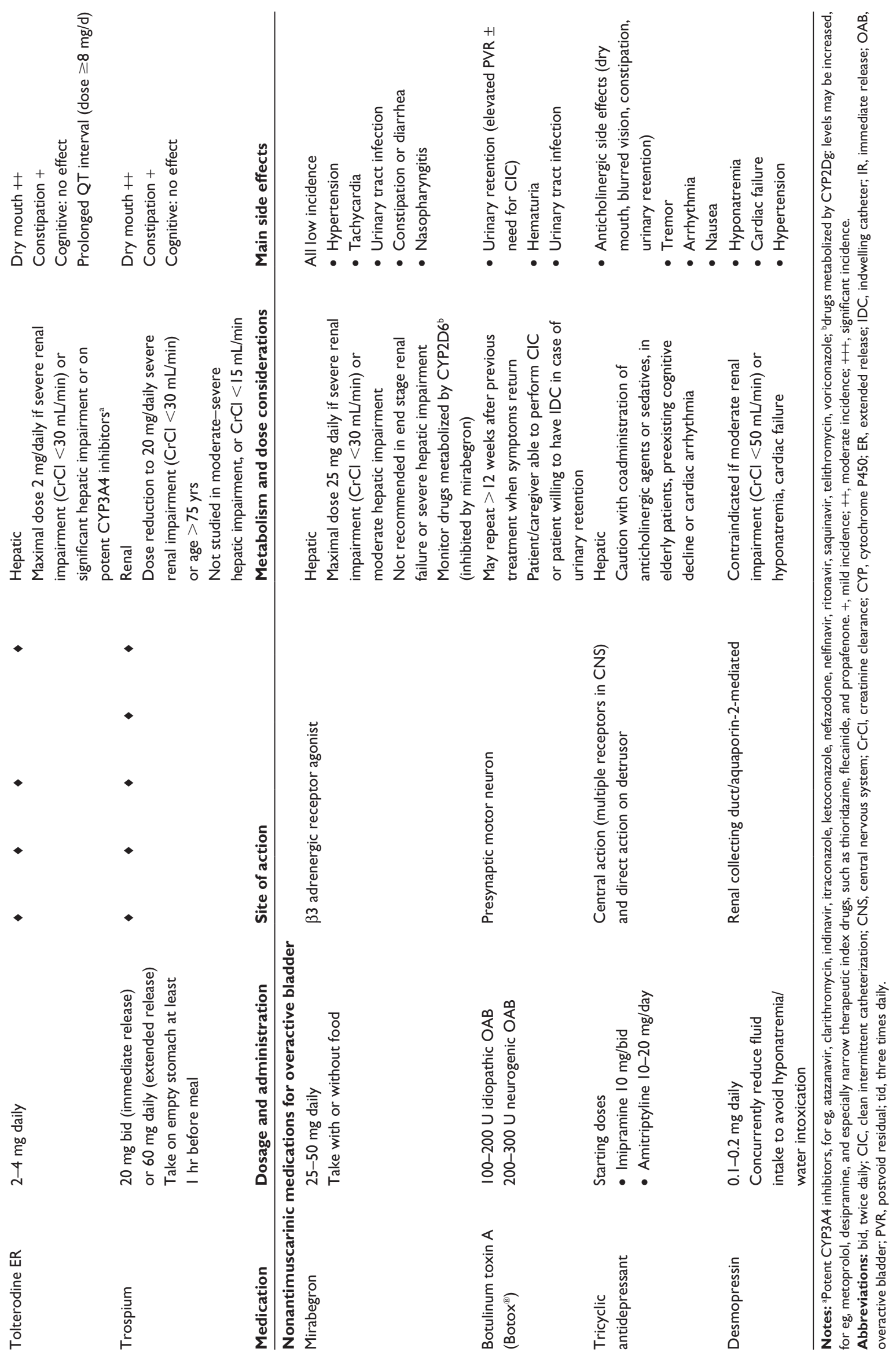


was better tolerated than OXY, with fewer withdrawals due to adverse events and less risk of dry mouth. ${ }^{19}$

Tolterodine significantly increases the cardiac QT interval at doses of $8 \mathrm{mg} /$ day or higher; hence, the recommended dose should not exceed $4 \mathrm{mg} /$ day. This is of particular relevance in patients with a history of known prolongation of QT interval, or who are taking class IA or III antiarrhythmic medications. ${ }^{18}$

Adverse effects are consistent with its antimuscarinic mechanism of action. The most common adverse events reported by patients receiving tolterodine-ER were dry mouth (23\%), headache $(6 \%)$, constipation $(6 \%)$, and abdominal pain $(4 \%){ }^{18}$

The effect of tolterodine on cognition was assessed in a crossover study of tolterodine-ER $4 \mathrm{mg}$ vs OXY-ER $20 \mathrm{mg}$. After 3 weeks, tolterodine was equivalent to placebo for the face recall test, with reduced scores in the OXY-ER group. ${ }^{20}$

\section{Fesoterodine fumarate}

Fesoterodine is an ER, competitive muscarinic receptor antagonist available as a $4 \mathrm{mg}$ or $8 \mathrm{mg}$ once-daily oral dose. After oral administration, fesoterodine cannot be detected in plasma, due to its rapid and extensive hydrolysis by serum esterases to 5-HMT, the same active metabolite as tolterodine. ${ }^{21}$ The lesser role of hepatic metabolism compared with tolterodine results in more consistent and predictable drug levels. The rapid metabolism and the low-moderate lipophilic nature of the molecule likely contribute to its minimal effect on cognition. A study comparing fesoterodine with placebo and an active control showed no detectable cognitive impairment at either the $4 \mathrm{mg}$ or $8 \mathrm{mg}$ dose of fesoterodine. ${ }^{22}$

Phase II and III placebo-controlled trials showed the most common adverse event was dry mouth, reported in $19 \%$ taking $4 \mathrm{mg}$ daily and $35 \%$ on $8 \mathrm{mg}$ daily. Only $0.4 \%-0.8 \%$ of patients discontinued fesoterodine due to dry mouth. Constipation occurred in $2 \%$ on placebo, $4 \%$ on $4 \mathrm{mg} /$ day, and $6 \%$ on $8 \mathrm{mg} /$ day. $^{21}$

The effect of fesoterodine on QT intervals at a therapeutic dose $(4 \mathrm{mg})$ and supratherapeutic dose $(28 \mathrm{mg})$ was evaluated in a double-blind, randomized, placebo-and positive-controlled (moxifloxacin $400 \mathrm{mg}$ ) parallel trial. Electrocardiographic measures during the trial showed no prolongation of QT interval with either dose of fesoterodine. ${ }^{23}$

Three trials comparing fesoterodine ( $8 \mathrm{mg} /$ day) to tolterodine-ER ( $4 \mathrm{mg} /$ daily) demonstrated that fesoterodine was superior to tolterodine across multiple outcome measures, including patient-reported cure or improvement, leakage episodes, frequency, and urgency episodes in 24 hours. ${ }^{24}$ However, fesoterodine had a comparatively higher risk of dry mouth and withdrawal due to adverse effects.

\section{Solifenacin}

Solifenacin is a competitive muscarinic receptor antagonist available as a $5 \mathrm{mg}$ or $10 \mathrm{mg}$ once-daily dose. It has selectivity for M3 muscarinic receptors.

Solifenacin undergoes hepatic metabolism and has a long half-life of 45-68 hours. This has implications for cessation of the drug following an adverse effect as symptoms may persist long after the drug is ceased. The long half-life does allow for reduced dosing, for eg, once every 2 days, for patients more susceptible to adverse effects, such as the frail and elderly.

In randomized, placebo-controlled trials to assess drug safety, the most common adverse effects were consistent with the anticholinergic nature of the drug, and were worse with the $10 \mathrm{mg}$ dose than with $5 \mathrm{mg}$. These side effects included dry mouth (10.9\% with $5 \mathrm{mg}$ vs $27.6 \%$ with $10 \mathrm{mg})$, constipation (5.4\% with $5 \mathrm{mg}$ vs $13.4 \%$ with $10 \mathrm{mg}$ ), and blurred vision (3.8\% with $5 \mathrm{mg}$ vs $4.8 \%$ with $10 \mathrm{mg}$ ). Although the $10 \mathrm{mg}$ dose is more efficacious for reducing frequency and urgency, it has a higher rate of side effects. ${ }^{19}$

A Cochrane review comparing anticholinergic agents used for OAB reported that solifenacin was superior to tolterodine regarding QOL, patient-reported cure or improvement, urgency, and leakage episodes in 24 hours. Although tolerance was equivalent, dry mouth rates (relative risk [RR] 0.69 , 95\% confidence interval [CI]: 0.51 to 0.94 ) were statistically significantly lower with solifenacin when compared with tolterodine-IR. Solifenacin has also been shown to have equivalent efficacy but with greater tolerance and QOL improvements than those provided by darifenacin. ${ }^{19}$

\section{Trospium chloride}

Trospium is a nonselective muscarinic receptor antagonist available as a $20 \mathrm{mg}$ IR tablet taken bid or a $60 \mathrm{mg}$ ER capsule for daily dosing. Pooled data from Phase III trials comparing trospium-ER $60 \mathrm{mg}$ with placebo showed a significantly greater reduction in nocturnal voids, diurnal voids, nocturnal and diurnal urge, and urinary incontinence episodes, favoring trospium. There was an associated significant improvement in sleep-related QOL, correlating with the reduction in nocturnal void 
frequency. ${ }^{25}$ A randomized, double-blind noninferiority study comparing trospium-IR with OXY-IR showed equivalency for UI outcomes but with less worsening of dry mouth in the trospium group. ${ }^{26}$

The chemical structure of the molecule and its low lipophilicity restricts transgression of the blood-brain barrier. A study evaluating the cognitive effect of trospium reported that in the presence of measureable peak plasma levels, trospium chloride was undetectable in cerebrospinal fluid (CSF) samples and that memory testing showed no significant impairment of learning or recall. ${ }^{27}$

The two most common adverse reactions reported by patients receiving trospium $20 \mathrm{mg}$ bid were dry mouth (20.1\%) and constipation (5.8\%). Dry mouth led to discontinuation in $1.9 \%$ of treated patients. ${ }^{28}$

\section{Darifenacin}

Darifenacin is a CR, highly bladder selective $\mathrm{M} 3$ receptor antagonist that is available as a $7.5 \mathrm{mg}$ or $15 \mathrm{mg}$ daily dose. Randomized, controlled trial data shows the superiority of darifenacin over placebo with regard to OAB symptoms and QOL. ${ }^{29}$ A study assessing the long-term efficacy and tolerability over a 2-year period showed significant improvements in OAB symptoms, which were sustained over 2 years. ${ }^{30}$ The most common adverse effects were dry mouth and constipation, which resulted in discontinuation in $2.3 \%$ and $4.2 \%$ of patients, respectively. Reported rates of constipation are $14.8 \%$ with $7.5 \mathrm{mg}$ daily and $21.3 \%$ with $15 \mathrm{mg}$ /daily, which is comparatively higher than with equivalent alternative anticholinergic agents. ${ }^{31}$

Two clinical trials assessing the cognitive effect of darifenacin showed no statistically significant difference from placebo. One study, in which OXY-ER was a comparator, showed no difference between darifenacin and placebo but a statistically significant decline in cognitive and memory end points with OXY-ER use. ${ }^{32}$ The second study, a prospective, randomized, open-label study, compared the selective agents solifenacin $5 \mathrm{mg}$ with darifenacin $7.5 \mathrm{mg}$ once daily. At 1 and 3 months of treatment, there was an equivalent reduction in all OAB symptoms in both treatment groups. However, solifenacin showed statistically greater improvements in QOL, better overall treatment satisfaction, and a decreased incidence of dry mouth after 3 months compared with the darifenacin group. ${ }^{33}$

\section{Propiverine}

Propiverine is a mixed-action drug with a nonselective antimuscarinic component and calcium channel-blocking effects.
The usual starting dose of propiverine-IR is $15 \mathrm{mg}$ bid and $30 \mathrm{mg}$ once daily for the ER formulation.

The comparative efficacy and tolerability of propiverine has been reported against placebo, tolterodine, solifenacin, and OXY. Several placebo-controlled studies have demonstrated a significant reduction in average micturition volume, frequency, number of incontinence episodes with propiverine (IR and ER formulations) compared to placebo, with a higher rate of dry mouth, blurred vision and constipation. ${ }^{34}$

In patients with idiopathic detrusor overactivity, a randomized, double-blind, multicenter trial compared propiverine-IR (15 mg bid) versus tolterodine ( $2 \mathrm{mg}$ bid). Propiverine was found to have comparable efficacy and QOL outcomes to tolterodine. Both groups showed significant improvements in maximum cystometric capacity, frequency, volume at first urge, and QOL. The rate of adverse effects, including dry mouth, was similar in both groups. ${ }^{35}$

A multicenter, randomized, double-blind Phase III trial involving 1584 patients with idiopathic OAB compared solifenacin 5 or $10 \mathrm{mg}$, propiverine $20 \mathrm{mg}$, and placebo. ${ }^{36}$ All active treatments versus placebo showed significantly superior improvement in mean voids per 24 hours, urgency and urgency incontinence, volume voided, and QOL. Of the active treatments, solifenacin $5 \mathrm{mg}$ caused less dry mouth. Solifenacin $10 \mathrm{mg}$ had a greater reduction in nocturia episodes, urge episodes, and increase in volume voided versus propiverine $20 \mathrm{mg}$ but had higher rates of dry mouth and constipation.

The combined results from two parallel trials comparing propiverine-IR and OXY-IR showed comparable improvement from baseline in regards to leakage episodes, micturitions per 24 hours, maximum cystometric capacity, and postvoid residual volume (PVR). ${ }^{19}$ Abrams et al reported greater efficacy of OXY-IR(15 mg daily) versus propiverine (IR $45 \mathrm{mg}$ daily or ER $30 \mathrm{mg}$ daily) for measured parameters of ambulatory urodynamics in a randomized, double-blind, placebo-controlled, crossover study. ${ }^{37}$ Those taking OXY had a significantly lower number, duration, and amplitude of involuntary detrusor contractions compared with the propiverine groups. OXY had a higher rate of dry mouth, and propiverine had a greater incidence of abnormal vision and constipation.

\section{Other nonanticholinergic agents Tricyclic antidepressant}

In the treatment of OAB, tricyclic antidepressants (TCAs) can exert effects on the CNS and directly on the lower urinary tract. TCAs are potent inhibitors of muscarinic, a-adrenergic, 
and histamine $\mathrm{H} 1$ receptors, and inhibit norepinephrine and serotonin reuptake at nerve terminals. In animal models, TCAs have been shown to reduce bladder contraction and increase the bladder volume required to initiate reflex voiding. ${ }^{38}$ An vitro study has also shown a direct inhibitory effect on detrusor muscle. ${ }^{39}$

The US Food and Drug Administration (FDA) has not approved the use of TCAs for OAB; however, these may be considered as second- or third-line therapy in an "off label" fashion, particularly as an adjunct to anticholinergic medication, for patients with refractory symptoms. The most commonly used TCAs for OAB are imipramine or amitriptyline.

The side effects of TCAs predominantly reflect their antimuscarinic properties. These include dry mouth, dry nose, constipation, drowsiness, arrhythmia, and urinary retention. Commencing with a low dose and increasing this slowly usually improves tolerance. Greater caution should be exercised in the context of combination therapy with anticholinergic agents, due to the risk of cumulative side effects, for eg, urinary retention or QT prolongation.

\section{Desmopressin}

Desmopressin acetate is a synthetic form of the antidiuretic hormone vasopressin and has been used for the treatment of nocturia and nocturnal enuresis in children and adults. The intranasal formulation is no longer indicated by the FDA for the treatment of primary nocturnal enuresis, due to the risk of severe hyponatremia and seizures.

A 2-week, Phase IIb double-blind, placebo-controlled, prospective, randomized, crossover study was conducted using $0.2 \mathrm{mg}$ of oral desmopressin in 88 adults suffering with OAB. ${ }^{40}$ Use of desmopressin was found to reduce the number of voids during the first 8 hours following treatment by one void $(3.2$ vs 4.2$)(P<0.001)$ and to decrease the number of urgency episodes compared with placebo during this period $(P<0.003)$. Of the 27 people who reported adverse events, all were mild, and no hyponatremia was recorded.

Another study compared the use of solifenacin $5 \mathrm{mg}$ with solifenacin $5 \mathrm{mg}$ plus desmopressin $0.2 \mathrm{mg}$, in a group of 68 women with OAB over a 2 -week period. ${ }^{41}$ The combination therapy did not significantly increase the time to the first void but did increase the time to the second and third voids and showed significant improvement in QOL scores.

In clinical practice, the use of desmopressin for $\mathrm{OAB}$ may have a limited role for short-term use in patients with primary nocturnal enuresis who do not have an underlying electrolyte disturbance or risk factors for hyponatremia. For older patients in particular, there is the risk of precipitating fluid retention, hyponatremia, and for worsening underlying cardiac failure.

\section{Hormone replacement therapy}

A systematic review of the effects of estrogen therapy on OAB symptoms in postmenopausal women showed a statistically significant improvement in frequency, urgency, first urge to void, and incontinence episodes. ${ }^{42}$ Both local and systemic therapies had similar outcomes, with the exception of nocturnal frequency, which was worsened with systemic therapies. Another review suggested a worsening of incontinence with systemic estrogen therapy. ${ }^{43}$

The synergistic value of topical estrogen therapy with an anticholinergic agent for the treatment of OAB symptoms is unclear. An unblinded, randomized trial involving 80 postmenopausal women with OAB compared use of tolterodine alone with tolterodine and vaginal estrogen combination therapy. ${ }^{44}$ Tolterodine $2 \mathrm{mg}$ bid was used in both groups, and vaginal estrogen was administered twice weekly. The combination therapy group showed comparatively greater improvement in mean daytime frequency, voided volume, and QOL. Nocturia, urgency, and urge incontinence rates improved similarly in both groups.

However, another study comparing tolterodine-ER $4 \mathrm{mg}$ daily to tolterodine-ER $4 \mathrm{mg}$ daily plus daily estriol application showed no difference in efficacy of treatment between the two groups after a 12 -week period. ${ }^{45}$

Thus, the use of topical estrogen therapy in postmenopausal women with OAB may improve symptoms; however, the long-term efficacy of this therapy is unclear.

\section{Mirabegron}

Mirabegron is the first $\beta 3$-AR agonist approved for the treatment of OAB. Detrusor relaxation during the storage phase of bladder filling is predominantly mediated by noradrenalin action on $\beta 1,2,3$-ARs. The $\beta 3$ subclass is thought to be most important in mediating human detrusor relaxation and is preferentially expressed on urinary bladder tissues. ${ }^{46}$ The main sites of action of mirabegron are the $\beta 3$-ARs on detrusor smooth muscle. These agents cause a dose-dependent relaxation of the detrusor muscle during bladder filling and inhibit detrusor overactivity. ${ }^{47}$

The alternative mechanism of action of mirabegron avoids the side effect profile typical of anticholinergic agents. Compared with the anticholinergic medications, the $\beta 3$-AR agonists increase bladder capacity with no change in 
micturition pressure or residual volume. ${ }^{48}$ Mirabegron has to date, been approved in Japan, the USA, Europe and Canada, for the treatment of symptoms of OAB.

Three large multicenter, randomized, double-blind, placebo-controlled Phase III trials evaluated the safety and efficacy of mirabegron, at once-daily doses of $50 \mathrm{mg}$ and $100 \mathrm{mg}$ in two studies and of $25 \mathrm{mg}$ and $50 \mathrm{mg}$ in the third. Tolterodine-ER $4 \mathrm{mg}$ was included as an active control arm in one trial. ${ }^{47,49,50}$ The safety, tolerability, and superior efficacy compared with placebo was demonstrated with all three doses of mirabegron.

A pooled analysis from the three studies reviewed the safety and efficacy of mirabegron $50 \mathrm{mg}$ and $100 \mathrm{mg}$ compared with placebo and the safety of mirabegron $25 \mathrm{mg}$ and tolterodine-ER $4 \mathrm{mg} .{ }^{51}$ The efficacy analysis of the $25 \mathrm{mg}$ dose was excluded from the pooled analysis as the data were obtained from only one trial. Mirabegron $50 \mathrm{mg}$ and $100 \mathrm{mg}$ demonstrated statistically significant improvements compared with placebo for the co-primary and secondary end points, including: mean number of incontinence episodes, micturitions and urgency episodes per 24 hours, mean micturition volume, and QOL outcomes.

Mirabegron was well tolerated, and the overall rates of treatment-related adverse events were similar across all doses of mirabegron ( $25 \mathrm{mg}, 50 \mathrm{mg}$, and $100 \mathrm{mg}$ ), placebo, and tolterodine-ER $4 \mathrm{mg}$.

The most common drug-related adverse events in the mirabegron group were hypertension and headache, which were of comparable incidence with placebo and tolterodine. Bothersome anticholinergic side effects, such as dry mouth, in the mirabegron group were comparable with those in the placebo group and lower than in the tolterodine group.

Across the three 12-week Phase III double blind, placebo-controlled studies receiving mirabegron $50 \mathrm{mg}$ once daily, there was a minimal change in cardiovascular parameters. The mean difference from placebo was approximately one beat per minute for pulse rate and approximately $1 \mathrm{mmHg}$ or less in systolic blood pressure/ diastolic blood pressure.

The recommended starting dose of mirabegron is $50 \mathrm{mg}$ once daily in Japan and Europe; in the USA, the recommended starting dose is $25 \mathrm{mg}$ once-daily, which can be increased to $50 \mathrm{mg}$ on an individual basis depending on efficacy and tolerability. The lower dose of $25 \mathrm{mg}$ is recommended in patients with severe renal impairment (glomerular filtration rate 15 to $29 \mathrm{~mL} / \mathrm{min} / 1.73 \mathrm{~m}^{2}$ ), moderate hepatic impairment (Child-Pugh Class B [http://www.accessdata.fda. gov/drugsatfda_docs/label/2012/202611s000lbl.pdf]).
Mirabegron prescribing information cautions against use in patients with severe uncontrolled hypertension (systolic blood pressure $\geq 180 \mathrm{mmHg}$ and/or diastolic blood pressure $\geq 110 \mathrm{mmHg}$ ) as the drug not been evaluated in this patient population. ${ }^{49,52}$

Caution should be exercised in patients with bladder outlet obstruction and in those receiving concurrent anticholinergic therapy for overactive bladder, due to the potential risk of urinary retention.

\section{Botulinum toxin}

Intradetrusor injection of botulinum toxin is an FDA-approved treatment option for patients with idiopathic and neurogenic $\mathrm{OAB} / \mathrm{DO}$ refractory to anticholinergic therapy.

Botulinum toxin is a potent neurotoxin derived from the bacterium Clostridium botulinum. There are seven distinct serotypes of botulinum toxin $(A-G)$. The majority of the literature regarding use in the lower urinary tract refers to BoNTA, specifically onabotulinumtoxinA (Botox); therefore, further discussion will be focused on Botox, noting that the alternative BoNTA formulation used in the bladder is Dysport $^{\circledR}$ (Ipsen, Boston, MA, USA) - the potency of these two BoNTA formulations is very different, and doses cannot be interchanged or converted.

\section{Mechanism of action}

The BoNTA molecule consists of a $100 \mathrm{kd}$ heavy chain and $50 \mathrm{kd}$ light chain. The heavy chain facilitates binding of BoNTA to the cell membrane of the presynaptic motor nerve and endocytosis into the cytoplasm. Once intracellular, the enzymatic action of the light chain is activated, leading to the cleavage of synaptosomal-associated protein 25 (SNAP-25), a protein that facilitates acetylcholine release from the presynaptic motor nerve. The inhibition of acetylcholine release at the neuromuscular junction decreases smooth and skeletal muscle activity. BoNTA similarly inhibits the release of sensory/afferent neurotransmitters, such as substance P, glutamate, and calcitonin gene-related peptide, contributing to its therapeutic effect in $\mathrm{OAB}$ by reducing sensitization of peripheral nerves. ${ }^{53}$

\section{Technique}

Intradetrusor injections of botulinum toxin can be performed with a rigid or flexible scope, under local or general anesthetic. Various injection protocols are described that differ in dosage, dilution, and in the number and location of injection sites. A common dilution of Botox is 100 units in 5-10 $\mathrm{mL}$ of normal saline, with $0.5-1 \mathrm{cc}$ injected per site. 
Retreatment may be considered when the clinical effect of the treatment wanes, which on average is between 3-9 months, but not to be performed earlier than 12 weeks following the previous treatment.

\section{Results in neurogenic detrusor overactivity}

Two pivotal multicenter placebo-controlled Phase III trials (total $n=691$ ) evaluated intradetrusor Botox $200 \mathrm{U}(\mathrm{n}=227)$, $300 \mathrm{U}(\mathrm{n}=223)$, or placebo $(\mathrm{n}=241)$ in patients with neurogenic DO and urinary incontinence resulting from multiple sclerosis and spinal cord injury. ${ }^{54,55}$ Both trials showed statistically significant improvement in UI episodes and cystometric measures with Botox $200 \mathrm{U}$ and $300 \mathrm{U}$ compared with placebo. The benefit of Botox over placebo was evident by week 2 posttreatment; ${ }^{54}$ and at 6 weeks, the mean reduction in UI episodes was $21(200 \mathrm{U})$ and 23 (300 U) episodes per week in the larger trial $(P<0.001)^{55}$ and $21.8(200 \mathrm{U})$ and $19.4(300 \mathrm{U})$ in the second trial $(P<0.01) .^{54}$

Pooled data showed maximum cystometric capacity (+153.6 mL with $200 \mathrm{U}$ vs $+11.9 \mathrm{~mL}$ with placebo), detrusor compliance $\left(+59.8 \mathrm{~mL} / \mathrm{cm} \mathrm{H}_{2} \mathrm{O}\right.$ with $200 \mathrm{U}$ vs -5.2 with placebo), maximum detrusor pressure during the first involuntary detrusor contraction, and Incontinence QOL score were significantly improved over those values in the placebo group. ${ }^{56}$

The median time to retreatment request by the patient was 36-42 weeks and was similar for the two doses of Botox and between the two trials. The most common adverse events were urinary tract infection and urinary retention. Of patients who did not catheterize at baseline, the need to commence clean intermittent catheterization (CIC) due to urinary retention increased in a dose-dependent fashion, with $10 \%$ on placebo, $35 \%$ on $200 \mathrm{U}$, and $42 \%$ on $300 \mathrm{U}$ initiating CIC. ${ }^{55}$ There was no clinically relevant benefit with $300 \mathrm{U}$ over $200 \mathrm{U}$ of Botox, with the $300 \mathrm{U}$ having greater adverse effects.

\section{Results in idiopathic overactive bladder}

Trials of Botox in patients with idiopathic OAB have included patients with urodynamic confirmed DO and those with only OAB symptoms. The optimal starting dose was established in a randomized, double-blind study involving 313 patients with idiopathic overactive bladder and urinary urgency incontinence, comparing 50,100, 150, 200, or $300 \mathrm{U}$ intradetrusor Botox with placebo. ${ }^{57}$ Durable efficacy in reducing urgency incontinence was observed for all the Botox dose groups of $100 \mathrm{U}$ or greater, with doses greater than $150 \mathrm{U}$ contributing minimal additional or clinically relevant improvement in symptoms. Furthermore, the duration of effect was similar between the different dose groups. There was a dose-dependent increase in PVR and need for CIC. The Botox dose of $100 \mathrm{U}$ provided the best balance between efficacy, adverse effects, and durability of effect for idiopathic OAB.

A large, double-blind, randomized, placebo-controlled study involved 548 patients with idiopathic OAB with inadequate response to anticholinergic therapy. ${ }^{58}$ The patients were randomized to receive intradetrusor injections of $100 \mathrm{U}$ Botox or placebo.

At 12 weeks, the patients receiving Botox, compared with the placebo group, had significantly greater improvements from baseline in urge incontinence episodes per day $(P<0.001)$; OAB symptoms, including frequency, urgency, and nocturia $(P \leq 0.01)$; and Incontinence QOL $(P<0.001)$. At 2 weeks, the Botox group had a greater rate of local side effects compared with the placebo group, with a higher PVR (46.9 mL versus $10.1 \mathrm{~mL}$ ) and higher rate of initiating CIC (6.9\% versus $0.7 \%)$. Overall, the Botox was well tolerated and demonstrated significant improvements in all OAB symptoms and QOL, for patients with persistent idiopathic OAB symptoms despite anticholinergics.

The typical duration of efficacy is 6-9 months, and efficacy appears to be comparable in subsequent injections. ${ }^{59}$

\section{Adverse effects}

The most frequently reported adverse reactions are local bladder symptoms, which occur within 12 weeks of treatment. In a large, randomized, placebo-controlled study, the rates of adverse effects in the group receiving Botox $100 \mathrm{U}$ were as follows: dysuria (12.2\%), bacteriuria (5.0\%), and urinary retention (5.4\%). ${ }^{60} \mathrm{~A}$ proportion of the Botox patients $(8.7 \%)$ had an increase in PVR volume of $>200 \mathrm{~mL}$ from baseline compared with placebo, for which there was no increase. Based on varying definitions, idiopathic trials of Botox showed that approximately $5 \%$ of patients developed urinary retention and up to $16 \%$ of patients required CIC until adequate detrusor contractility returned. The risk of migration of botulinum toxin away from the detrusor, causing systemic adverse events, such as hyposthenia, is extremely uncommon with Botox. ${ }^{53}$

\section{Pharmacotherapy for overactive bladder: compliance, quality of life and patient satisfaction Quality of life and patient satisfaction}

OAB has a considerable detrimental effect on multiple domains of patient QOL. The QOL burden of OAB patients is reflected in their health utility scores, which are amongst 
the lowest when compared with other chronic conditions, such as asthma, diabetes, heart disease, malignancy, and migraine headaches. ${ }^{61}$

Randomized, double-blind, placebo-controlled trials have shown a significant QOL improvement in patients with OAB compared with placebo, following the use of anticholinergics, mirabegron, and botulinum toxin. ${ }^{19}$

A Cochrane review of anticholinergic agents used for $\mathrm{OAB}^{19}$ showed ER anticholinergic formulations appear to have superior QOL improvements compared with the IR forms. When compared with tolterodine-IR, OXY-IR had a similar QOL profile, whilst solifenacin demonstrated superior efficacy and QOL. In three trials, fesoterodine had improved efficacy and QOL improvements compared with tolterodine-ER. ${ }^{19}$ The SOLIDAR study compared the selective antimuscarinic agents solifenacin $(5 \mathrm{mg})$ and darifenacin $(7.5 \mathrm{mg})$. The two active agents showed equivalence with regard to OAB symptom outcomes, but solifenacin showed statistically greater improvements in QOL, better overall treatment satisfaction, and decreased incidence of dry mouth, after 3 months.

Three Phase III clinical trials investigated the efficacy and safety of mirabegron vs placebo. Tolterodine-ER $4 \mathrm{mg}$ was included as an active control in one study. Compared with tolterodine-ER $4 \mathrm{mg}$ and placebo, all mirabegron doses demonstrated quicker and superior improvement in healthrelated QOL and efficacy $(P<0.05) .^{62}$

In idiopathic and neurogenic $\mathrm{OAB}$ patients inadequately managed by anticholinergics, level 1 evidence has shown that intradetrusor BoNTA is well tolerated and results in clinically significant improvements in all OAB symptoms, patient-reported benefit, and health-related QOL when compared with placebo. ${ }^{55,58}$

\section{Patient compliance}

Patient compliance may prove a challenge to the successful medical management of OAB, due to the often long-term nature of therapy and potential side effects of the agents used. Persistence with treatment may be lower than with other chronic conditions.

A retrospective review of prescription data for oral anticholinergic drugs prescribed in the UK over a 12-month period analyzed persistence with treatment, in patients who were newly commenced on a particular anticholinergic drug or dosage. ${ }^{63}$

The following agents were reviewed: darifenacin, flavoxate, OXY (ER and IR), propiverine, solifenacin, tolterodine (ER and IR), and trospium. Tolterodine-ER had the greatest number of prescriptions.

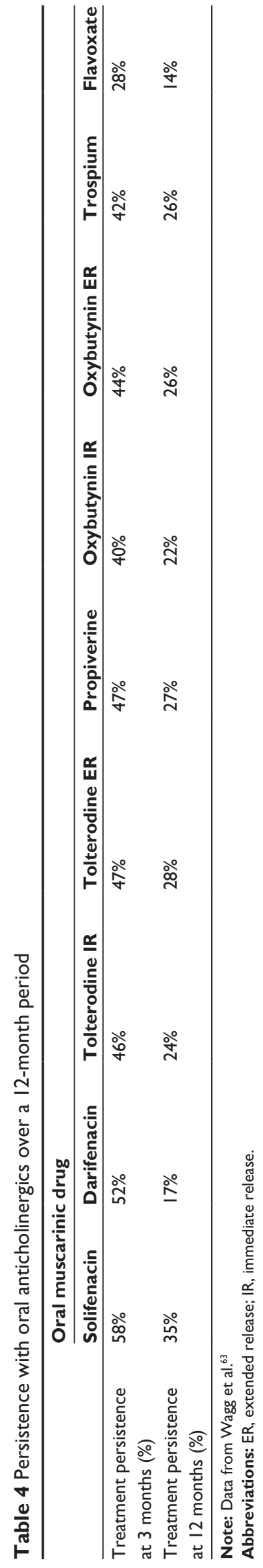


Patient persistence with treatment was generally poor across the board over the 12-month period (Table 4). Of the reviewed medications, persistence with treatment was best for solifenacin (187 days versus 77-157 days for the other treatments), and older patients ( $\geq 60$ years) were more likely to persist with treatment than were patients aged $40-59$ years.

\section{Conclusion}

Pharmacotherapy for OAB has been predominantly focused on blocking the postsynaptic muscarinic receptors on the detrusor muscle, to decrease involuntary detrusor contractions. Their use may be limited by efficacy, tolerability, and long-term compliance.

The anticholinergics are generally comparable regarding efficacy and have a similar core side effect profile relating to their mechanism of action. Clinical variations between formulations arise from differences in pharmacokinetics, uroselectivity, chemical structure, and route of metabolism. The CR and transdermal preparations are associated with fewer adverse effects.

A selective M3-receptor antagonist with low lipophilicity (and therefore low propensity for crossing the blood-brain barrier) may be considered in patients with concerns about cognitive function. However, the presence of $\mathrm{M} 3$ receptors on the bowel make these selective receptor antagonists more prone to exacerbating constipation.

Use of a $\beta 3$ agonist or botulinum toxin obviates the above concerns. These newer agents have proven efficacy and tolerability and demonstrate quicker and more significant improvement in QOL compared with anticholinergic medications. These provide further treatment options for patients intolerant or refractory to anticholinergic agents.

Older nonanticholinergic medications, such as tricyclic antidepressants, vasopressin, and hormonal therapy, may play a role as an adjunct to first-line therapy. Further studies are required to determine the role, safety, and efficacy of combination therapy with first-line anticholinergics and the newer therapies.

\section{Disclosure}

Dr SB Radomski received honorarium from Astellas, Pfizer, Allergan and Watson for work as an advisory board member. The authors report no other conflicts of interest in this work.

\section{References}

1. Abrams P, Cardozo L, Fall M, et al; Standardization Sub-Committee of the International Continence Society. The standardization of terminology in lower urinary tract function: report from the standardization sub-committee of the International Continence Society. Urology. 2003;61(1):37-49.
2. Radomski SB, Barkin J. Medical management of overactive bladder. Can J Urol. 2012;19 Suppl 1:2-9.

3. Burgio KL, Locher JL, Goode PS. Combined behavioral and drug therapy for urge incontinence in older women. $J$ Am Geriatr Soc. 2000;48(4):370-374.

4. Christofi N, Hextall A. An evidence-based approach to lifestyle interventions in urogynaecology. Menopause Int. 2007;13(4):154-158.

5. Fowler CJ, Griffiths D, de Groat WC. The neural control of micturition. Nat Rev Neurosci. 2008;9(6):453-466.

6. Jamshidi R, Moore A, Park A, et al. Reference Guide for Clinicians: Diagnosis and Management of Overactive Bladder. Washington, DC: Association of Reproductive Health Professionals; 2011. Available from: http://www.arhp.org/uploadDocs/OABQRG.pdf. Accessed September 27, 2013.

7. Wagg A. The cognitive burden of anticholinergics in the elderly implications for the treatment of overactive bladder. Eur Urol Rev. 2012;7(1):42-49

8. Ditropan ${ }^{\circledast}$ (oxybutynin chloride) tablets and syrup [prescribing information]. Mountain View, CA: ALZA Corp; 2008. http://www. accessdata.fda.gov/drugsatfda_docs/label/2008/017577s034,018211s 017,020897s018lbl.pdf. Accessed October 18, 2013.

9. Pagoria D, O’Connor RC, Guralnick ML. Antimuscarinic drugs: review of the cognitive impact when used to treat overactive bladder in elderly patients. Curr Urol Rep. 2011;12(5):351-357.

10. Barkin J, Corcos J, Radomski S, et al; UROMAX Study Group. A randomized, double-blind, parallel-group comparison of controlled- and immediate-release oxybutynin chloride in urge urinary incontinence. Clin Ther. 2004;26(7):1026-1036.

11. Anderson RU, Mobley D, Blank B, Saltzstein D, Susset J, Brown JS. Once daily controlled versus immediate release oxybutynin chloride for urge urinary incontinence. OROS Oxybutynin Study Group. J Urol. 1999;161(6):1809-1812.

12. Kennelly MJ. A comparative review of oxybutynin chloride formulations: pharmacokinetics and therapeutic efficacy in overactive bladder. Rev Urol. 2010;12(1):12-19.

13. Dmochowski RR, Nitti V, Staskin D, Luber K, Appell R, Davila GW. Transdermal oxybutynin in the treatment of adults with overactive bladder: combined results of two randomized clinical trials. World $J$ Urol. 2005;23(4):263-270.

14. Davila GW, Daugherty CA, Sanders SW; Transdermal Oxybutynin Study Group. A short-term, multicenter, randomized double-blind dose titration study of the efficacy and anticholinergic side effects of transdermal compared to immediate release oral oxybutynin treatment of patients with urge urinary incontinence. J Urol. 2001;166(1): 140-145.

15. Dmochowski RR, Sand PK, Zinner NR, Gittelman MC, Davila GW, Sanders SW; Transdermal Oxybutynin Study Group. Comparative efficacy and safety of transdermal oxybutynin and oral tolterodine versus placebo in previously treated patients with urge and mixed urinary incontinence. Urology. 2003;62(2):237-242.

16. Staskin DR, Dmochowski RR, Sand PK, et al. Efficacy and safety of oxybutynin chloride topical gel for overactive bladder: a randomized, double-blind, placebo controlled, multicenter study. J Urol. 2009;181(4):1764-1772.

17. Kay GG, Staskin DR, MacDiarmid S, McIlwain M, Dahl NV. Cognitive effects of oxybutynin chloride topical gel in older healthy subjects: a 1-week, randomized, double-blind, placebo- and active-controlled study. Clin Drug Investig. 2012;32(10):707-714.

18. Detrol ${ }^{\circledR}$ (tolterodine tartrate) tablets [prescribing information]. New York, NY: Pfizer, Inc; 2012. Available from: http://www.accessdata. fda.gov/drugsatfda_docs/label/2008/020771s019,021228s012lbl.pdf. Accessed October, 2013.

19. Madhuvrata P, Cody JD, Ellis G, Herbison GP, Hay-Smith EJ. Which anticholinergic drug for overactive bladder symptoms in adults [review]. Cochrane Database Syst Rev. 2012;1:CD005429.

20. Kay G, Crook T, Rekeda L, et al. Differential effects of the antimuscarinic agents darifenacin and oxybutynin ER on memory in older subjects. Eur Urol. 2006;50(2):317-326. 
21. Toviaz ${ }^{\circledR}$ (fesoterodine fumarate) extended-release tablets [prescribing information]. New York, NY: Pfizer, Inc; 2012. Available from: http:// www.accessdata.fda.gov/drugsatfda_docs/label/2008/022030lbl.pdf. Accessed October 18, 2013.

22. Kay GG, Maruff P, Scholfield D, et al. Evaluation of cognitive function in healthy older subjects treated with fesoterodine. Postgrad Med. 2012;124(3):7-15

23. Malhotra B, Wood N, Sachse R, Gandelman K. Thorough QT study of the effect of fesoterodine on cardiac repolarization. Int J Clin Pharmacol Ther. 2010;48(5):309-318.

24. Chapple CR, Van Kerrebroeck PE, Jünemann KP, Wang JT, Brodsky M. Comparison of fesoterodine and tolterodine in patients with overactive bladder. BJU Int. 2008;102(9):1128-1132.

25. Ginsberg DA, Oefelein MG, Ellsworth PI. Once-daily administration of trospium chloride extended release provides 24 -hr coverage of nocturnal and diurnal symptoms of overactive bladder: an integrated analysis of two phase III trials. Neurourol Urodyn. 2011;30(4): 563-567.

26. Zellner M, Madersbacher H, Palmtag H, Stöhrer M, Bödeker RH; P195 Study Group. Trospium chloride and oxybutynin hydrochloride in a german study of adults with urinary urge incontinence: results of a 12-week, multicenter, randomized, double-blind, parallel-group, flexible-dose noninferiority trial. Clin Ther. 2009;31(11): 2519-2539.

27. Staskin D, Kay G, Tannenbaum C, et al. Trospium chloride has no effect on memory testing and is assay undetectable in the central nervous system of older patients with overactive bladder. Int J Clin Pract. 2010;64(9):1294-1300.

28. $\operatorname{Trosec}^{\circledast}$ (trospium chloride) coated tablets [prescribing information]. Mississauga, ON: Sunovion Pharmaceuticals Canada Inc; 2012. Available from: http://www.accessdata.fda.gov/drugsatfda_docs/ label/2012/021595s009lbl.pdf. Accessed October 18, 2013.

29. Chapple C, DuBeau C, Ebinger U, Rekeda L, Viegas A. Darifenacin treatment of patients $\geq 65$ years with overactive bladder: results of a randomized, controlled, 12-week trial. Curr Med Res Opin. 2007;23(10): 2347-2358.

30. Hill S, Elhilali M, Millard RJ, et al. Long-term darifenacin treatment for overactive bladder in patients aged 65 years and older: analysis of results from a 2-year, open-label extension study. Curr Med Res Opin. 2007;23(11):2697-2704.

31. Enablex ${ }^{\circledast}$ (darifenacin) extended-release tablets [prescribing information]. Stein, Switzerland: Novartis Pharma Stein AG; 20008. Available from: http://www.accessdata.fda.gov/drugsatfda_docs/ label/2010/021513s006lbl.pdf. Accessed October 18, 2013.

32. Lipton RB, Kolodner K, Wesnes K. Assessment of cognitive function of the elderly population: effects of darifenacin. $J$ Urol. 2005;173(2):493-498.

33. But I, Goldstajn MS, Oresković S. Comparison of two selective muscarinic receptor antagonists (solifenacin and darifenacin) in women with overactive bladder - the SOLIDAR study. Coll Antropol. 2012;36(4): 1347-1353.

34. Asimakopoulos AD, Cerruto MA, Del Popolo G, et al. An overview on mixed action drugs for the treatment of overactive bladder and detrusor overactivity. Urol Int. 2012;89(3):259-269.

35. Jünemann KP, Halaska M, Rittstein T, et al. Propiverine versus tolterodine: efficacy and tolerability in patients with overactive bladder. Eur Urol. 2005;48(3):478-482.

36. Yamaguchi O, Marui E, Kakizaki H, et al; Japanese Solifenacin Study Group. Randomized, double-blind, placebo- and propiverine-controlled trial of the once-daily antimuscarinic agent solifenacin in Japanese patients with overactive bladder. BJU Int. 2007;100(3):579-587.

37. Abrams P, Cardozo L, Chapple C, Serdarevic D, Hargreaves K, Khullar V; 1032 Study Group. Comparison of the efficacy, safety, and tolerability of propiverine and oxybutynin for the treatment of overactive bladder syndrome. Int J Urol. 2006;13(6):692-698.

38. Kreder K, Dmochowski R, editors. The Overactive Bladder: Evaluation and Management. London: Informa Healthcare; 2007.

39. Olubadewo JO. The effect of imipramine on rat detrusor muscle contractility. Arch Int Pharmacodyn Ther. 1980;245(1):84-94.
40. Hashim H, Malmberg L, Graugaard-Jensen C, Abrams P. Desmopressin, as a "designer-drug," in the treatment of overactive bladder syndrome. Neurourol Urodyn. 2009;28(1):40-46.

41. Han YK, Lee WK, Lee SH, Yang DY, Kim H. Effect of desmopressin with anticholinergics in female patients with overactive bladder. Korean J Urol. 2011;52(6):396-400.

42. Cardozo L, Lose G, McClish D, Versi E. A systematic review of the effects of estrogens for symptoms suggestive of overactive bladder. Acta Obstet Gynecol Scand. 2004;83(10):892-897.

43. Cody JD, Jacobs ML, Richardson K, Moehrer B, Hextall A. Oestrogen therapy for urinary incontinence in post-menopausal women [review]. Cochrane Database Syst Rev. 2012;10:CD00140.

44. Tseng LH, Wang AC, Chang YL, Soong YK, Lloyd LK, Ko YJ. Randomized comparison of tolterodine with vaginal estrogen cream versus tolterodine alone for the treatment of postmenopausal women with overactive bladder syndrome. Neurourol Urodyn. 2009;28(1): $47-51$.

45. Serati M, Salvatore S, Uccella S, Cardozo L, Bolis P. Is there a synergistic effect of topical oestrogens when administered with antimuscarinics in the treatment of symptomatic detrusor overactivity? Eur Urol. 2009;55(3):713-719.

46. Sacco E, Bientinesi R. Mirabegron: a review of recent data and its prospects in the management of overactive bladder. Ther Adv Urol. 2012;4(6):315-324.

47. Khullar V, Amarenco G, Angulo JC, et al. Efficacy and tolerability of mirabegron, a $\beta(3)$-adrenoceptor agonist, in patients with overactive bladder: results from a randomised European-Australian phase 3 trial. Eur Urol. 2013;63(2):283-295.

48. Takasu T, Ukai M, Sato S, et al. Effect of (R)-2-(2-aminothiazol-4-yl)4'-\{2-[(2-hydroxy-2-phenylethyl)amino]ethyl $\}$ acetanilide (YM178), a novel selective beta3-adrenoceptor agonist, on bladder function. J Pharmacol Exp Ther. 2007;321(2):642-647.

49. Nitti VW, Auerbach S, Martin N, Calhoun A, Lee M, Herschorn S. Results of a randomized phase III trial of mirabegron in patients with overactive bladder. J Urol. 2013;189(4):1388-1395.

50. Herschorn S, Barkin J, Castro-Diaz D, et al. A phase III, randomized, double-blind, parallel-group, placebo-controlled, multicentre study to assess the efficacy and safety of the $\beta_{3}$ adrenoceptor agonist, mirabegron, in patients with symptoms of overactive bladder. Urology. 2013;82(2):313-320.

51. Nitti VW, Khullar V, van Kerrebroeck P, et al. Mirabegron for the treatment of overactive bladder: a prespecified pooled efficacy analysis and pooled safety analysis of three randomised, double-blind, placebo-controlled, phase III studies. Int J Clin Pract. 2013;67(7): 619-632.

52. Chapple CR, Kaplan SA, Mitcheson D, et al. Randomized double-blind, active-controlled phase 3 study to assess 12-month safety and efficacy of mirabegron, a $\beta(3)$-adrenoceptor agonist, in overactive bladder. Eur Urol. 2013;63(2):296-305.

53. Nitti VW. Botulinum toxin for the treatment of idiopathic and neurogenic overactive bladder: state of the art. Rev Urol. 2006;8(4): 198-208.

54. Cruz F, Herschorn S, Aliotta P, et al. Efficacy and safety of onabotulinumtoxinA in patients with urinary incontinence due to neurogenic detrusor overactivity: a randomised, double-blind, placebo-controlled trial. Eur Urol. 2011;60(4):742-750.

55. Ginsberg D, Gousse A, Keppenne V, et al. Phase 3 efficacy and tolerability study of onabotulinumtoxinA for urinary incontinence from neurogenic detrusor overactivity. J Urol. 2012;187(6):2131-2139.

56. Rovner E, Dmochowski R, Chapple C, Thompson C, Lam W, Haag-Molkenteller C. OnabotulinumtoxinA improves urodynamic outcomes in patients with neurogenic detrusor overactivity. Neurourol Urodyn. Epub February 6, 2013.

57. Dmochowski R, Chapple C, Nitti VW, et al. Efficacy and safety of onabotulinumtoxinA for idiopathic overactive bladder: a double-blind, placebo controlled, randomized, dose ranging trial. J Urol. 2010;184(6): 2416-2422. 
58. Chapple C, Sievert KD, MacDiarmid S, et al. OnabotulinumtoxinA $100 \mathrm{U}$ significantly improves all idiopathic overactive bladder symptoms and quality of life in patients with overactive bladder and urinary incontinence: a randomised, double-blind, placebo-controlled trial. Eur Urol. 2013;64(2):249-256.

59. Granese R, Adile G, Gugliotta G, Cucinella G, Saitta S, Adile B. Botox $\left({ }^{\circledR}\right)$ for idiopathic overactive bladder: efficacy, duration and safety. Effectiveness of subsequent injection. Arch Gynecol Obstet. 2012;286(4):923-929.

60. Nitti VW, Dmochowski R, Herschorn S, et al; EMBARK Study Group. OnabotulinumtoxinA for the treatment of patients with overactive bladder and urinary incontinence: results of a phase 3, randomized, placebo controlled trial. J Urol. 2013;189(6):2186-2193.
61. Mittmann N, Trakas K, Risebrough N, Liu BA. Utility scores for chronic conditions in a community-dwelling population. Pharmacoeconomics. 1999;15(4):369-376.

62. Pavesi M, Devlin N, Hakimi Z, et al. Understanding the effects on HR-QoL of treatment for overactive bladder: a detailed analysis of EQ-5D clinical trial data for mirabegron. J Med Econ. 2013;16(7): 866-876.

63. Wagg A, Compion G, Fahey A, Siddiqui E. Persistence with prescribed antimuscarinic therapy for overactive bladder: a UK experience. BJU Int. 2012;110(11):1767-1774.

\section{Publish your work in this journal}

Research and Reports in Urology is an international, peer-reviewed, open access journal publishing original research, reports, editorials, reviews and commentaries on all aspects of adult and pediatric urology in the clinic and laboratory including the following topics: Pathology, pathophysiology of urological disease; Investigation and treatment of

\section{Dovepress}

urological disease; Pharmacology of drugs used for the treatment of urological disease. The manuscript management system is completely online and includes a very quick and fair peer-review system, which is all easy to use. Visit http://www.dovepress.com/testimonials.php to read real quotes from published authors.

Submit your manuscript here: http://www.dovepress.com/research-and-reports-in-urology-journal 